\title{
Predictors of mortality among a cohort of HIV/AIDS patients on anti-retroviral therapy in coastal South India
}

Nithin Kumar, Shodhan Aithal, Bhaskaran Unnikrishnan, John Ramapuram, Rekha Thapar,
Prasanna Mithra, Vaman Kulkarni, Ramesh Holla

Kasturba Medical College, Mangalore, Manipal University, India

\begin{abstract}
Introduction: As the number of patients on anti-retroviral therapy (ART) rises, it is important to identify factors that predict mortality among these patients so that they can be closely monitored. Aim of the study was to determine the mortality rate among a cohort of HIV patients on naïve ART and to assess the predictors of mortality among them.

Material and methods: In this retrospective study, records of 249 patients living with HIV (PLHIV) who were ART naïve, enrolled in the ART centre attached to Kasturba Medical College Hospital, Mangalore from February 2012 to February 2015, were analysed. Univariate and multivariate logistic regression was carried out to assess the factors predicting mortality among these patients.

Results: By the end of the study period, 47 out of 249 patients died, giving an overall mortality rate of $18.8 \%$. The mean age of the PLHIV was $43.4 \pm 9.1$ years. WHO stage $3 / 4$ disease was present in $47.4 \%$ of patients. On univariate analysis, mortality was found to be significantly associated with alcohol consumption, being non-ambulatory, underweight (body mass index [BMI] $<18.5 \mathrm{~kg} / \mathrm{m}^{2}$ ), WHO stage 3 or 4 disease, presence of opportunistic infections (OIs), presence of tuberculosis, being on an efavirenz-based regimen, poor adherence $(<95 \%)$, CD4 count $<350$ cells $/ \mathrm{mm}^{3}$, anaemia and raised creatinine levels. However, on multivariate analysis, presence of OIs and low BMI were found to independently predict mortality.
\end{abstract}

Conclusions: Our study identifies lower BMI and presence of OIs as independent risk factors predicting mortality.

HIV AIDS Rev 2017; 16: 18-23

DOI: https://doi.org/10.5114/hivar.2017.65124

Key words: mortality, predictors, ART, cohort, India.

\section{Introduction}

Human immunodeficiency virus (HIV) infection is caused by a retrovirus which leads to acquired immune deficiency syndrome (AIDS). The virus affects CD4 cells and destroys them, which results in a poor immune response to various organisms, leading to opportunistic infections and AIDS-related neoplasms [1].

Globally, 35 million people are infected with the retrovirus and about 1.5 million people die due to HIV infection every year. HIV has reached epidemic proportions in India, with a prevalence of $0.27 \%$ among the general population
Address for correspondence: Dr. Nithin Kumar, MD, Assoc. Prof., Department of Community Medicine, Kasturba Medical College (Manipal University), 575001 Mangalore, Karnataka, India, e-mail: nithin.gatty@manipal.edu

\section{Article history:}

Received: 17.06.2016

Received in revised form: 13.08.2016

Accepted: 01.11.2016

Available online: 16.01.2017
International Journal of HIV-Related Problems

HIV \& AIDS

$R$ e $v$ i e w 
and an incidence of 0.116 million cases every year. The majority of these cases are in the age group of 15-49 years. It is also the $8^{\text {th }}$ leading cause of death in India, accounting for $3 \%$ of mortality in the country, affecting the national economy $[2,3]$. The state of Karnataka contributes to $10 \%$ of India's HIV burden with the prevalence of HIV being $0.53 \%$ among the general population, which is almost two times the national level [4].

Antiretroviral therapy (ART) for HIV/AIDS was started in 1987 with the drug zidovudine. After initiation of ART, HIV infection has now turned into a chronic disease. About 0.8 million and 0.112 million patients living with HIV (PLHIV) are on ART in India and Karnataka respectively. Though the introduction of ART and increased coverage of ART facilities have reduced mortality and incidence (0.274 million in 2000 compared to 0.116 million in 2011), still 147,729 and 13,514 deaths occur every year in India and Karnataka respectively due to AIDS [5].

The above statistics on AIDS-related death are quite significant and demand improvement in ART. As the number of patients on treatment rises, it is important to identify factors that predict a higher risk of mortality so that they can be closely monitored. A detailed study of factors affecting mortality among PLHIV is necessary in order to improve ART and to reduce mortality associated with AIDS. Quite a few studies from other nations have identified the predictors of mortality among HIV/AIDS patients after ART initiation and many factors (adherence, CD4 count, body mass index [BMI], haemoglobin \% etc.) were found to be associated with mortality [6]. However, such data from our nation are limited, especially from the study area, justifying the need for this study. The district of Dakshina Kannada has a prevalence of HIV/AIDS of more than $1 \%$ among the general population from the past 3 years, which is very significant and hence was chosen as the study area.

With this background the current study was carried out to determine the mortality rate among a cohort of HIV patients on ART and to assess the predictors of mortality among them.

\section{Material and methods}

This retrospective cohort study was conducted during May-June 2015 in an ART centre attached to Kasturba Medical College Hospital in Attavar, Mangalore. Among a total of 438 PLHIV above 18 years of age who had enrolled in the above-mentioned ART centre for treatment from February 2012 to February 2015 (3 years), 249 patients who were ART naïve were included in this study. ART naïve patients were those who had not received ART before February 2012 and were put on ART for the first time during the study period. PLHIV who were initiated on ART before February 2012 were excluded from the study. The patients were initiated on ART if they had a CD4 count $<350$ cells $/ \mathrm{mm}^{3}$ [7] or were in WHO stage 3 or stage $4[7,8]$. HIV infected females who were on ART exclusively to prevent vertical transmission were excluded.
Approval was obtained from the Institutional Ethics Committee of Kasturba Medical College, Mangalore (Manipal University), India. The data were captured from records of PLHIV receiving ART using a data extraction sheet. The extraction sheet had 3 sections: general participant information, clinical/laboratory investigations and treatment details, which included information on functional status of the patient, WHO staging, CD4 count, opportunistic infections (OIs), drugs for OIs, number of pills, adherence etc.

\section{Data analysis}

The collected data were entered in and analysed using SPSS (Statistical Package for Social Sciences) version 11.5 (SPSS, Inc., Chicago, IL, USA). The data were expressed in terms of descriptive statistics (mean [standard deviation] and median [IQR]) and proportions. The difference between quantitative variables (biochemical and clinical parameters) among outcome groups (alive/deceased) was tested using the independent $t$-test/Mann-Whitney test and $P<0.05$ was considered statistically significant. Univariate and multivariate analysis was conducted to assess the various factors predicting mortality among patients on ART. $P<0.05$ was considered evidence of a statistically significant association between predictive and outcome variables. Only the factors found to be significant on univariate analysis were considered for multivariate analysis. Unadjusted and adjusted odds ratios (ORs) and corresponding 95\% confidence intervals (CIs) were also reported.

\section{Results}

A total of 249 naive patients were enrolled for ART during February 2012 to February 2015 (107 patients were enrolled in 2012, 50 in 2013 and 92 in 2014). By the end of study period, 47 out of 249 patients died, giving an overall mortality rate of $18.8 \%$ (21 patients on ART died in 2012, 13 in 2013 and 13 in 2014). The AIDS death to treatment ratio (ratio of number of deaths to number of patients enrolled in a year) in 2012 was 19.6, 26 in 2013 and 14.1 in 2014. Out of the 47 patients who died by the end of study period, the majority $(63.8 \%, n=30)$ were male. Among the 18 cases for which the cause of death was reported, tuberculosis and its sequelae accounted for $50 \%(n=13)$ of deaths and AIDS-related malignancy was the cause of death among 5 patients.

The median duration of follow-up of the patients was 21 months (IQR: 8-32). The mean age of the PLHIV was $43.4 \pm 9.1$ years, with the majority $(n=160,64.2 \%)$ below 45 years of age. A higher proportion of the patients were male $(n=147,59 \%)$, married $(n=169,67.8 \%)$ and earning $\leq 5000$ rupees (Rs) per month ( $n=136,54.6 \%)$. The majority of the patients were from the district of Dakshina Kannada $(61.4 \%, n=153)$, where the ART centre was located, followed by Kasaragod $(16.4 \%, n=41)$ and Udupi $(7.2 \%$, $n=18) .35 .7 \%(n=89)$ of the patients had family members who had HIV/AIDS. Smoking and alcohol consumption was 
Table 1. Comparison of baseline characteristics among study participants $(N=249)$

\begin{tabular}{l|c|c|c|c}
\hline \multirow{2}{*}{ Variable } & \multicolumn{2}{|c|}{ Living status } & \multirow{2}{*}{$\begin{array}{c}\text { Total } \\
(N=249)\end{array}$} & \multirow{2}{*}{$P$ value* $^{*}$} \\
\cline { 2 - 3 } & Alive $(n=202)$ & Dead $(n=47)$ & Mean (SD & \\
\cline { 2 - 3 } & Mean (SD) & Mean (SD) & $43.4(9.0)$ & 0.846 \\
\hline Age (years) & $43.5(9.1)$ & $43.2(8.9)$ & $20.0(3.4)$ & 0.004 \\
\hline BMI $\left(\mathrm{kg} / \mathrm{m}^{2}\right)$ & $20.3(3.4)$ & $18.4(3.5)$ & $11.8(2.3)$ & 0.001 \\
\hline Haemoglobin $(\mathrm{gm} / \mathrm{dl})$ & $12.0(2.1)$ & $10.5(2.7)$ & \\
\hline
\end{tabular}

*Independent t-test was done

Table 2. Comparison of baseline clinical characteristics among study population $(N=249)$

\begin{tabular}{l|c|c|c|c}
\hline \multirow{2}{*}{ Variable } & Alive $(n=202)$ & Dead $(n=47)$ & Total $(N=249)$ & \multirow{2}{*}{$P$ value $^{*}$} \\
\cline { 2 - 4 } & Median (IQR) & Median (IQR) & Median (IQR) & 0.043 \\
\hline CD4 count (cells/mm³) & $277(148-400)$ & $208(133-351)$ & $270(147-387)$ & 0.001 \\
\hline ESR (mm/hour) & $40(17-75)$ & $85(48-100)$ & $46(22-82)$ & 0.273 \\
\hline Platelets (million cells/dl) & $0.22(0.16-0.27)$ & $0.19(0.12-0.27)$ & $0.21(0.15-0.26)$ & 0.050 \\
\hline Urea $(\mathrm{mg} / \mathrm{dl})$ & $19(16-23)$ & $23(16-33)$ & $19(16-24)$ & 0.516 \\
\hline Creatinine $(\mathrm{mg} / \mathrm{dl})$ & $0.8(0.7-1.0)$ & $0.85(0.7-1.2)$ & $0.8(0.7-1.0)$ & 0.709 \\
\hline Bilirubin $(\mathrm{mg} / \mathrm{dl})$ & $0.4(0.3-0.6)$ & $0.3(0.3-0.7)$ & $0.4(0.3-0.6)$ & 0.014 \\
\hline ALT $(\mathrm{IU} / \mathrm{IU} / \mathrm{l})$ & $29(23-40)$ & $36(27-56)$ & $30(23-43)$ & 0.217 \\
\hline
\end{tabular}

*Mann-Whitney test was done

present in $16.4 \%(n=41)$ and $33.7 \%(n=84)$ of the patients respectively.

Nearly $20.9 \%(n=52)$ of patients were underweight $\left(\mathrm{BMI}<18.5 \mathrm{~kg} / \mathrm{m}^{2}\right)$. WHO stage 3 and 4 disease was present in $47.4 \%(n=118)$ of patients. OIs were present in $49.4 \%$ $(n=123)$, the most common being tuberculosis $(n=59$, $48 \%)$. Poor adherence $(<95 \%)$ was noted among 3.6\% $(n=9)$ of the patients.

A comparison of mean baseline characteristics among the study cohort is depicted in Table 1.

Significantly lower BMI and haemoglobin levels were observed among the deceased when compared to patients who are alive $(P<0.05)$.

When the laboratory parameters were studied across the groups (Table 2), it was observed that the deceased patients had a significantly lower CD4 count, and higher erythrocyte sedimentation rate (ESR) and aspartate transaminase (AST) values as compared to patients who were alive $(P<0.05)$.

Univariate analysis was carried out to determine the factors associated with mortality among the HIV cohort. Among the demographic factors, patients aged $>45$ years, of male gender, patients who are married, with an income of $<5000$ Rs/month, ambulatory/bedridden patients, without HIV-positive family members, smokers and patients who consumed alcohol were found to have higher mortality. However, only alcohol consumption and not working due to illness were found to be statistically significant $(P<0.05)$.

Among the clinical parameters, a statistically significant association $(P<0.05)$ with mortality was observed among patients who were underweight $\left(\mathrm{BMI}<18.5 \mathrm{~kg} / \mathrm{m}^{2}\right)$, those with WHO stage 3 or 4 disease, presence of OIs, presence of tuberculosis, patients on an efavirenz based regimen and those with poor adherence $(<95 \%)$. Patients on a zidovudine-based regimen had higher mortality than patients on a tenofovir-based regimen, but this association was not found to be significant $(P>0.05)$.

Among the laboratory parameters, a CD4 count $<350$ cells $/ \mathrm{mm}^{3}$, anaemia $(\mathrm{Hb}<12 \mathrm{~g} / \mathrm{dl})$ and raised creatinine levels were found to be significantly associated with mortality in univariate analysis.

Table 3 shows the univariate and multivariate analysis of the factors associated with mortality. Only the factors significant in univariate analysis were considered for multivariate analysis. Among the factors found significant in univariate analysis, presence of OIs and low BMI were the two factors found to significantly predict mortality in multivariate analysis.

\section{Discussion}

Scaling up of free ART in India since 2004 has saved the lives of around 1.5 lakh PLHIV, resulting in a $42 \%$ decline in HIV-related deaths during 2007 to 2011 [5].

However, mortality associated with HIV still remains high even after anti-retroviral therapy is made available free of cost to patients, especially in resource-limited settings. The reasons for mortality vary across regions, ranging from late initiation to therapy, non-compliance to treatment or 
Table 3. Factors predicting mortality of PLHIV $(N=249)$

\begin{tabular}{|c|c|c|c|c|}
\hline Factors & $\begin{array}{l}\text { Unadjusted OR } \\
\qquad(95 \% \mathrm{Cl})\end{array}$ & $P$ value & $\begin{array}{c}\text { Adjusted OR } \\
(95 \% \mathrm{CI})\end{array}$ & $P$ value \\
\hline \multicolumn{5}{|l|}{ Alcohol consumption } \\
\hline Yes & $2.15(1.10-4.23)$ & 0.025 & $1.02(0.20-5.23)$ & 0.978 \\
\hline No & 1 & & & \\
\hline \multicolumn{5}{|l|}{ Body mass index $\left(\mathrm{kg} / \mathrm{m}^{2}\right)$} \\
\hline Low & $7.58(3.47-16.56)$ & 0.000 & $11.17(2.28-54.77)$ & 0.003 \\
\hline Normal & 1 & & & \\
\hline Overweight & $1.4(0.5-3.9)$ & 0.585 & & \\
\hline Obese & $0.6(0.1-2.6)$ & 0.739 & & \\
\hline \multicolumn{5}{|l|}{ Opportunistic infections } \\
\hline Present & $3.77(1.85-7.70)$ & 0.000 & $14.517(1.33-158.1)$ & 0.028 \\
\hline Absent & 1 & & & \\
\hline \multicolumn{5}{|l|}{ Working status } \\
\hline Ambulatory/bedridden & $6.57(3.15-13.68)$ & 0.000 & $3.38(0.56-20.34)$ & 0.182 \\
\hline Working & 1 & & & \\
\hline \multicolumn{5}{|l|}{ WHO staging } \\
\hline Stage $3 \& 4$ & $20.31(7.60-54.25)$ & 0.000 & $10.25(0.98-107.01)$ & 0.052 \\
\hline Stage $1 \& 2$ & 1 & & & \\
\hline \multicolumn{5}{|l|}{ Adherence } \\
\hline$<95 \%$ & $18.70(4.34-80.57)$ & 0.000 & $4.94(0.30-81.65)$ & 0.264 \\
\hline$>95 \%$ & 1 & & & \\
\hline \multicolumn{5}{|l|}{ TB co-infection } \\
\hline Yes & $4.39(2.15-8.95)$ & 0.000 & $0.0001 .40(0.26-7.38)$ & 0.691 \\
\hline No & 1 & & & \\
\hline \multicolumn{5}{|l|}{ Regimen } \\
\hline Efavirenz based & $2.78(1.22-6.33)$ & 0.015 & $1.02(0.18-5.51)$ & 0.980 \\
\hline Nevirapine based & 1 & & & \\
\hline \multicolumn{5}{|l|}{ CD4 count (cells/mm³) } \\
\hline$<350$ & $4.63(2.13-8.55)$ & 0.000 & $1.30(0.28-6.16)$ & 0.738 \\
\hline$>350$ & 1 & & & \\
\hline \multicolumn{5}{|l|}{ Haemoglobin (gm/dl) } \\
\hline$<12$ & $2.34(1.02-5.38)$ & 0.046 & $1.11(0.22-5.56)$ & 0.894 \\
\hline$>12$ & 1 & & & \\
\hline \multicolumn{5}{|l|}{ Blood creatinine level } \\
\hline Raised creatinine & $5.06(1.32-19.34)$ & 0.018 & $4.15(0.15-118.94)$ & 0.405 \\
\hline Normal & 1 & & & \\
\hline
\end{tabular}

presence of OIs. The knowledge of these factors responsible for mortality among PLHIV can guide the policy makers to address them, suggesting and implementing remedial measures through the program.

The mortality rate in our study cohort was $14.4 \%$, which was higher than in similar studies conducted in Africa [9-11], which is probably due to the higher number of deceased patients in WHO stage 3/4 of the disease in our study.
Alcohol consumption, low BMI, presence of OIs, WHO stage 3/4 disease, ambulatory/bedridden functional status, poor adherence, low CD4 count, anaemia, leukocytopenia, raised AST and raised creatinine were found to be significant factors associated with mortality among our study cohort. However, low BMI $\left(\mathrm{BMI}<18.5 \mathrm{~kg} / \mathrm{m}^{2}\right)$ and presence of OIs were found to be independently associated with mortality. Complications related to nutritional status among HIV- 
-infected patients still remain a challenge in the ART era. Even in settings where access to ART is not limited, weight loss associated with disease progression is an issue of concern for any AIDS care physician [12]. Malnutrition plays an important role in rapid deterioration of HIV patients, resulting from immune depletion and HIV progression. HIV infection as it progresses creates a state where a patient is unable to procure, utilize or consume food, which in turn fuels the already depleted immune suppression. Malnourishment depresses the immune system, creating a vicious cycle among PLHIV and making them more prone to OIs, increasing the risk of mortality [13]. Nutrition for Healthy Living (NFHL) data showed that weight loss of $1 \%$ with each visit increased the risk of dying by $11 \%$. It also showed that BMI was inversely associated with risk of death. Malnutrition is a predictor of worse outcomes in both HIV-infected adults and children, and identifying and treating malnutrition at its earliest can halt disease progression [12].

Undernutrition, measured in terms of BMI in our study, was an independent predictor of mortality. Studies from the Sub-Saharan African region have observed a similar trend, with respect to the role of nutrition in PLHIV. Low BMI was associated with mortality in studies from Burkino Faso [9, 14], northern Ethiopia [10] and Nigeria [11], where, as in studies from Tanzania [6] and Ethiopia [15], history of significant weight loss, and weight less than $45 \mathrm{~kg}$ were predictors of mortality. Poor nutritional status at the initiation of ART and its deterioration within the first 3 months of starting therapy was an important predictor of mortality in another study from Tanzania [16]. These findings are significant since once initiated with ART, BMI starts improving [17]. Immune reconstitution inflammatory syndrome (IRIS), which is a usual sequela following initiation of therapy, also needs to be managed [18]. Nutritional status however needs to be maintained among patients on ART, especially in resource poor settings, where food security issues play a major role. The data from NFHL studies have proved that use of highly active antiretroviral therapy (HAART) has not negated the concern of weight loss among HIV-infected individuals [12]. With an improved nutritional status, PLHIV can tolerate the long-term side effects of the ART drugs.

Lower circulating CD4+ cell counts are also associated with lower weight [12], causing further decline of immunity and giving rise to various OIs and neoplasms. Presence of OIs was another independent predictor of mortality in our study. Among the OIs, TB was more common. The pattern of OIs varies across countries and from patient to patient. TB is more common in developing countries, especially India, where OIs such as Kaposi sarcoma and Mycobacterium avium complex (MAC), often reported from developed countries, are rare [19].

Similar studies from different parts of India have reported tuberculosis to be the most important cause of mortality [20-23]. In a study from South Africa, presence of cryptococcal meningitis or oral candidiasis was an important predictor of mortality [24]. Presence of OIs such as tuberculosis indicates stage 3 of the disease and CD $4<200$ cells/dl [8], both of which were found to be associated with mortality in our study. WHO stage 3/4 of HIV and reduced CD4 counts were an important factor for mortality in studies from across the world $[9-11,14,15,20,25,26]$.

The treatment of tuberculosis in PLHIV is complex and takes into account the patient's requirement for ART, potential drug reactions, shared drug toxicities and complications related to the IRIS $[18,27]$. Presence of multidrug resistant (MDR) and extensively drug resistant (XDR) tuberculosis with the barrage of 2 nd line drugs used for its treatment further complicates the treatment of HIV. ART is usually started 2 weeks after initiation of anti-tuberculosis treatment (ATT), but not later than 2 months [7], to check whether the patient is able to tolerate the ATT. First-line ATT drugs such as pyrazinamide, isoniazid and rifampicin have all been associated with hepatotoxicity and when combined with non-nucleoside reverse transcriptase inhibitors (NNRTIs)such as nevirapine and efavirenz can further increase the risk [28].

Laboratory parameters such as haemoglobin $<12 \mathrm{gm} / \mathrm{dl}$, leukopenia, raised creatinine and raised aspartate transaminase (AST) were found to be associated with mortality in our study. Anaemia as a predictor of mortality was reported in studies from Africa [8, 9, 14, 24, 25]. Measuring the laboratory parameters to check for haematological toxicity, hepatotoxicity and renal toxicity before initiation of ART and at periodic intervals is recommended in the National ART guidelines [2].

Poor adherence to medication was also found to be an important factor for mortality among PLHIV on ART in our study. Poor adherence leads to clinical failure, resulting in poor CD4 count, giving rise to OIs, and thereby increasing the risk of mortality. Various studies conducted across the globe have reported that poor adherence to ART increases mortality $[15,28,29]$. The results from our study as well as from similar studies across the world have pointed towards a variety of factors which predict mortality among PLHIV. However, on closer observations each of these factors seems to be related to each other, one factor being a direct outcome of the other. The limitation of this study is that as data were collected using records, a few of the data could not be collected as the data were not collected for research purposes.

\section{Conclusions}

Our study identifies lower BMI and presence of OIs as independent risk factors predicting mortality among PLHIV on ART. Thus, initiating ART in a newly HIV-infected patient does not necessarily reduce his risk of dying. Importance has to be given to improving his nutritional status, right from the time of diagnosis and initiation of treatment. Nutritional statuses in terms of weight gain and BMI, along with frequent monitoring of laboratory parameters such as haemoglobin and liver enzymes and regular screening for OIs, has to be carried out. Nutritional supplementation of underweight on ART should be given on a regular basis, and provision of an uninterrupted supply of drugs, maintaining good adherence practices and prophylaxis against opportunistic infections should be provided. 


\section{Acknowledgment}

The authors acknowledge the support provided by the Infectious Disease Cell, Department of Medicine, Kasturba Medical College, Mangalore. We would also like to thank the Department of Community Medicine and Manipal University for encouraging research and its publication in international journals of repute.

\section{Conflict of interest}

The author's declared no potential conflicts of interest with respect to the research, authorship, and/or publication of this article.

\section{References}

1. HIV Overview. HIV/AIDS: The Basics. Retrieved from: https:// aidsinfo.nih.gov/education-materials/fact-sheets/19/45/hiv-aids-the-basics (2015).

2. National AIDS Control Organization. Number of PLHIV alive and on ART at the end of September 2014. Retrieved from: http://www. naco.gov.in/upload/2014\%20mslns/PLHIV\%20alive\%20and\%20 on\%20ART \%20September\%202014.pdf (2014).

3. Centers for Disease Control and Prevention. CDC Factsheet in India. Retrieved from: http://www.cdc.gov/globalhealth/countries/ india/pdf/india.pdf (2014).

4. Ministry of Health and Family Welfare, Government of India. State fact sheets, 2014. Retrieved from: http://naco.gov.in/upload/2014\%20 mslns/State\%20Fact\%20Sheet\%202013-14.pdf (2014).

5. Department of AIDS Control. Ministry of Health \& Family Welfare. Government of India. Annual Report 2013-14. Retrieved from: http://www.naco.gov.in/upload/2014\%20mslns/NACO_English\%202013-14.pdf (2014).

6. Mageda K, Leyna GH, Mmbaga EJ. High Initial HIV/AIDS-related mortality and-its predictors among patients on antiretroviral therapy in the Kagera Region of Tanzania: a five-year retrospective cohort study. AIDS Res Treat 2012; 2012: 843598.

7. Department of AIDS Control. National AIDS Control Organization, Ministry of Health \& Family Welfare. Government of India. Anti-Retroviral Therapy guidelines for HIV infected Adults and Adolescents 2013. Retrieved from: http://www.naco.gov.in/upload/ Policies\%20\&\%20Guidelines/Antiretroviral\%20Therapy\%20 Guidelines\%20for\%20HIV-Infected\%20Adults\%20and\%20Adolescents.pdf (2013).

8. World Health Organization. WHO case definitions of HIV for surveillance and revised clinical staging and immunological classification of HIV-related disease in adults and children. Retrieved from: http:// www.who.int/hiv/pub/guidelines/HIVstaging150307.pdf (2007).

9. Poda A, Hema A, Zoungrana J, et al. Mortality of HIV-Infected Patients on Antiretroviral Therapy in a Large Public Cohort in West Africa, Burkina Faso: Frequency and Associated Factors. Adv Infect Dis 2013; 3: 281-289.

10. Tadesse K, Haile F, Hiruy N. Predictors of mortality among patients enrolled on antiretroviral therapy in Aksum Hospital, Northern Ethiopia: a retrospective cohort study. PLoS One 2014; 9: e87392.

11. Eguzo KN, Lawal AK, Eseigbe CE, et al. Determinants of Mortality among Adult HIV-Infected Patients on Antiretroviral Therapy in a Rural Hospital in South-Eastern Nigeria: A 5-Year Cohort Study. AIDS Res Treat 2014; 867827.

12. Mangili A, Murman DH, Zampini AM, et al. Nutrition and HIV infection: review of weight loss and wasting in the era of highly active antiretroviral therapy from the nutrition for healthy living cohort. Clin Infect Dis 2006; 42: 836-842.
13. Duggal S, Chugh TD, Duggal AK, et al. HIV and malnutrition: effects on immune system. Clin Dev Immunol 2012; 2012: 784740.

14. Kouanda S, Meda IB, Nikiema L, et al. Determinants and causes of mortality in HIV-infected patients receiving antiretroviral therapy in Burkina Faso: a five-year retrospective cohort study. AIDS Care 2012; 24: 478-490.

15. Biadgilign S, Reda AA, Digaffe T. Predictors of mortality among HIV infected patients taking antiretroviral treatment in Ethiopia: a retrospective cohort study. AIDS Res Ther 2012; 9: 15.

16. Liu E, Spiegelman D, Semu H, et al. Nutritional status and mortality among HIV-infected patients receiving antiretroviral therapy in Tanzania. J Infect Dis 2011; 204: 282-290.

17. De Pee S, Semba RD. Role of nutrition in HIV infection: review of evidence for more effective programming in resource-limited settings. Food Nutr Bull 2010; 31: S313-S344.

18. New York State Department of Health AIDS Institute, Immune Reconstitution Inflammatory Syndrome (IRIS) in HIV-infected patients (2009). Retrieved from: http://cdn.hivguidelines.org/wp-content/uploads/2009/08/Immune Reconstitution-Inflammatory.pdf

19. Kumarasamy N, Vallabhaneni S, Flanigan TP, et al. Clinical profile of HIV in India. Indian J Med Res 2005; 121: 377-394. Retrieved from: http://icmr.nic.in/ijmr/2005/april/0414.pdf

20. Ghate M, Deshpande S, Tripathy S, et al. Mortality in HIV infected individuals in Pune, India. Indian J Med Res 2011; 133: 414-420.

21. Bhowmik A, Bhandari S, De R, et al. Predictors of mortality among HIV-infected patients initiating anti-retroviral therapy at a tertiary care hospital in eastern India. Asian Pac J Trop Med 2012; 5: 986-990 .

22. Alvarez-Uria G, Naik PK, Pakam R, et al. Factors associated with attrition, mortality, and loss to follow up after antiretroviral therapy initiation: data from an HIV cohort study in India. Glob Health Action 2013; 6: 21682.

23. Javalkar P, Prakash R, Isac S, et al. An Estimation of Mortality Risks among People Living with HIV in Karnataka State, India: Learnings from an Intensive HIV/AIDS Care and Support Programme. PLoS One 2016; 11: e0156611.

24. Zhyvytsia D. Mortality and its predictors among highly active antiretroviral therapy naive HIV-infected individuals: data from prospective cohort study in Ukraine. Georgian Med News 2014; 232-233: 69-74.

25. Ojikutu BO, Zheng H, Walensky RP, et al. Predictors of mortality in patients initiating antiretroviral therapy in Durban, South Africa. S Afr Med J 2008; 98: 204-208.

26. Fregonese F, Collins IJ, Jourdain G, et al. Predictors of 5-year mortality in HIV-infected adults starting highly active antiretroviral therapy in Thailand. J Acquir Immune Defic Syndr 2012; 60: 91-98.

27. Sterling TR. Treatment of pulmonary tuberculosis in HIV-infected adults (2015). Retrieved from:http://www.uptodate.com/contents/ treatment-of-pulmonary-tuberculosis-in-hiv-infected-adults.

28. Hambisa MT, Ali A, Dessie Y. Determinants of mortality among HIV positives after initiating antiretroviral therapy in Western Ethiopia: a hospital-based retrospective cohort study. ISRN AIDS 2013; 2013: 491601.

29. Focà E, Odolini S, Sulis G, et al. Clinical and immunological outcomes according to adherence to first-line HAART in a urban and rural cohort of HIV-infected patients in Burkina Faso, West Africa. BMC Infect Dis 2014; 14: 153. 